\title{
Risk Aversion and Emotions in DoND
}

\author{
Mehmet Burak Kahyaoğlu ${ }^{1} \&$ Özgür İ́can ${ }^{1}$ \\ ${ }^{1}$ Faculty of Economics and Administrative Sciences, Ondokuz Mayıs University, Samsun, Turkey \\ Correspondence: Özgür İcan, Faculty of Economics and Administrative Sciences, Ondokuz Mayıs University, \\ Samsun, ON. Kurupelit Campus, P. O. Box: 55139 Atakum, Turkey. Tel: 90-362-312-1919/6054. E-mail: \\ ozgur.ican@omu.edu.tr
}

Received: November 1, 2016

Accepted: November 15, 2016 Online Published: December 14, 2016

doi:10.5539/ijef.v9n1p32

URL: http://dx.doi.org/10.5539/ijef.v9n1p32

\begin{abstract}
Contrary to the traditional economic school of thought, emotions known to have a huge effect on cognitive processes leading to decisions. In this context, it can be observed that some television shows provide a very appropriate test-bed for examining decision-making behavior under risk. This study attempts to estimate the degree of Arrow-Pratt RRA for a group of decision-makers composed of 101 "Deal or No Deal" TV show contestants. For further analysis, a "face-reading" software was employed in order to identify emotions experienced by contestants at various parts of the game, and the influence of such emotions on the risk aversion behavior. Our findings suggest that emotions have an influence on the decisions of the contestants.
\end{abstract}

Keywords: decision making under risk, risk aversion, emotion recognition

\section{Introduction}

Attitudes towards risk play an important role in accounting for substantial part of decisions and behaviors of individuals (Deck et al., 2008). In today's world, timing and size of risks taken by individuals are very critical for their economic life in particular. Based on the significance of this matter, a wide range of theories that have very different hypotheses have been developed to examine risky decisions. In economic literature, although a reference is mainly made to the Expected Utility Theory (Von Neuman \& Morgenstern, 1947) to explain decision-making behavior under uncertainty, form 1970s many behavioral patterns were identified that conflicted with that theory as a result of contributions especially from psychology and neurology, and the Prospect Theory was suggested by Kahneman and Tversky (1979) as a strong alternative to the Expected Utility Theory. In other words, it is determined that, on contrary to traditional thought of economy, emotions effectively play an active role in cognitive processes in terms of a number of ways of decision-making (Clore et al., 1994; Forgas, 1995). Similarly, Lerner and Keltner (2001) suggest that emotions stimulate changes in cognition, psychology and action. Based on our day-to-day experiences, Schwarz (2000) pointed out that there was no doubt our emotions had influence of decisions we made, and likewise consequence of most of our decisions had influence of our emotions. The complex of emotions, cognition and decision-making interplays and the interest in this issue of researchers is limited but increases day by day. Elster (1998) emphasized that the role of emotions was critical in the process of making social and economic decisions of people. With advanced technology, neural findings of relationship between emotions and decisions were begun to reveal as a result of functional brain imaging and neuropsychosocial studies in particular (Seymour \& Dolan, 2008).

Although the risky decisions constitute a basis for almost all branches of economy, it is very difficult to empirically test and prove such theories. The major reason for this is that risky choices of individuals for problems they encounter in real life are mostly beyond being direct observation of researchers. Post et al. (2008) expresses that being unaware of actual probability distribution of events encountered by individuals in daily life and of their belief, and decisions in real life that are rarely based on exact probabilities bring additional challenges to investigating the issue. Due to mentioned challenges, the relevant leading empirical studies appear to being based on experiments and responds to hypothetical questions. Although laboratory and classroom experiments provide researchers with advantage of controlling probability distribution of choice alternatives, the bets are either determined hypothetically due to restrictions on budget being exposed, or kept at very low level. Deck et al. (2008) indicate that this prevents participants from acting optimally and causes to remain incapable to reveal their real choice. To avoid such handicaps, researchers have performed their experience in relatively low-income countries (Note 1). Again due to restrictions on budget, the bets used could not be in excess of a 
monthly wage in that country in such studies. It is suggested that this resulted in insignificant correlation of findings for risk attitudes based on expectations with lifelong wealth of individuals, and in findings being invalid for higher amounts.

At this point, television shows, due to their characteristics, provide a very appropriate dataset to examine decision-making behavior under risk. Examples include "Card Sharks" (Robert, 1993), "Jeopardy!" (Andrew, 1995), "Illinois Instant Riches" (Philip \& Gerald, 1997), "Lingo" (Roel \& Peter, 2001), "Hoosier Millionaire" (Fullenkamp et al., 2003) and "Who Wants to be a Millionaire?" (Hartley et al., 2006). Television shows are considered ideal natural experiments to investigate rational choice and decision-making under risk. The advantages provided by television shows are basically summarized as follows (Botti et al., 2008; Roos \& Sarafidis, 2010; Deck et al., 2008; Post et al., 2008; Andersen et al., 2008);

- There are real bets with large amount.

- Decision problems experienced by contestants are simpler and better defined than those encountered in real life.

This study investigated the influence of emotions on risk aversion behavior of individuals based on behavior of participants in "Deal or No Deal" (DoND) broadcasted by many countries worldwide. Andersen et al. (2014) point out that behaviors observed in DoND program offer an excellent opportunity to examine dynamic decision-making under controlled uncertainty. Favorable design features of the game to examine risk aversion behavior include real bets, presence of bets with very low amount as well as very high amount, simple probability distribution, minimal knowledge, skill and strategy required, and that contestants never have to pay out of pocket. In the relevant literature, there are 3 types of empirical strategies implemented in order to investigate DoND behaviors observed. They are:

\section{- Calculation of CRRA limits}

- Review of specific decisions that allow testing exact propositions of Expected Utility Theory.

- Proposition for implicit decision process using maximum likelihood and estimation of structural parameters of this process

In the present study, the degree of Arrow-Pratt Relative Risk Aversion (RRA) was estimated for a total of 101 DoND contestants with 90 from Turkey, 11 from the USA, 20 from Australia, and 31 from Indonesia. Then the "face reading" software was used to identify emotions experienced by contestants at various parts of the game, and the influence of such emotions that were revealed endogenously throughout the game on the risk aversion behavior. As a result of analyses, a number of findings indicated that emotions that were revealed endogenously in the DoND game had influence on the decisions of contestants. The section 1 of the study details the game and dataset. The section 2 calculates the RRA parameters of participants using bounds approach. The section 3 of the study includes the literature investigating the influence of emotions on decision-making and risk aversion. Finally, the section 4 includes findings of the study and recommendations for future studies.

\section{Method}

The DoND game was developed by Endemol, the producer, and first broadcasted in Holland in 2002. The basic features of the game are almost the same in versions of the game in different countries except that amount in the boxes may differ. There are 26 boxes in standard and widely used version of the game, and 26 different monetary amounts are randomly distributed to these 26 boxes with a wide range of monetary amount (from minimum $\$ 0.1$ and to maximum $\$ 1.000 .000$ ). Nobody in the game knows which box contains what monetary reward, except an independent observer in the game. The contestant choses one box among 26 boxes and wins the monetary reward in the box. In the first round, the contestant choses 5 boxes out of 25 other than his/her own box and asks the other contestant holding the box to open it. The person called the "bank" requests to buy the box of the contestant for some money offered by the bank. If the contestant accepts the offer, the game will end. If the contestant does not accept the offer, the contestant will then ask the other contestants to open 4 boxes in the second round of the game and receive another offer. The contestant makes 3 boxes opened in the third round, 2 boxes in the fourth round, and 1 box each in the fifth, sixth, seventh and eighth rounds and receives an offer for each round. There are 2 boxes left unopened in the ninth round. One of them is the contestant's own box that she/he takes in the beginning of the game. If the contestant does not accept the offer in this round, then she/he will win the monetary reward contained in her/his own box. The dataset includes a total of 62 contestants with 20 from Australia, 11 from the USA, and 31 from Indonesia in this version of the game. The dataset includes totally 24 boxes in Turkish version of the game and the contestant opens 5, 3, 3, 3, 3, 3 and 2 boxes in the rounds. In this version, the game consists of maximum 7 rounds and when the seventh offer is not accepted, then the 
contestant will win the reward in her/his own box. The dataset includes 39 contestants from Turkey in this version of the game.

The video of contestant in the game was acquired on the internet searching for videos containing full version of the show from various video websites. As required by the format, socioeconomic and demographic characteristics of contestants were obtained from brief interview made with participants before the game began. Table 1 provides characteristics of the sample.

The amount of offers made by the bank in each round is largely associated with the expected value contained in unopened boxes. As the contestant makes boxes with small amount opened in the rounds, the expected value is increased, thus the offer is increased. As the contestant makes boxes with high amount opened, the expected value is reduced, thus the amount of offer is reduced. The decision of the contestant to proceed or end the game depends on belief of the bank for future offers. Besides amounts contained in unopened boxes, the number of unopened boxes also affects the statistical distribution. From point of view of contestants, a round in which boxes with small amount are opened is considered a favorable round.

Table 1. Distribution of sample

\begin{tabular}{|c|c|c|c|c|c|c|c|c|c|c|c|}
\hline \multirow[t]{2}{*}{ Country } & \multicolumn{2}{|c|}{ Gender } & \multicolumn{3}{|c|}{ Age } & \multicolumn{2}{|c|}{ Job Status } & \multicolumn{2}{|c|}{ Marital Status } & \multicolumn{2}{|c|}{ Educaiton } \\
\hline & Female & Male & $18-25$ & $26-40$ & $41-$ & Employed & Jobless & Married & Bachelor & Secondary School & Higher Edu. \\
\hline & $\%$ & $\%$ & $\%$ & $\%$ & $\%$ & $\%$ & $\%$ & $\%$ & $\%$ & $\%$ & $\%$ \\
\hline Turkey & 43 & 57 & 33 & 25 & 42 & 20 & 80 & 66 & 34 & 25 & 75 \\
\hline USA & 45 & 55 & 0 & 72 & 28 & 81 & 19 & 9 & 91 & 72 & 28 \\
\hline Indonesia & 32 & 68 & 32 & 62 & 6 & 45 & 55 & 20 & 80 & 41 & 59 \\
\hline Australia & 20 & 80 & 15 & 85 & 0 & 65 & 35 & 35 & 65 & 62 & 38 \\
\hline Total & 38 & 62 & 26 & 55 & 19 & 44 & 56 & 35 & 65 & 42 & 58 \\
\hline
\end{tabular}

Therefore, the probability that the amount is high contained in the box as well as the offer to be proposed will be increased. As more boxes are opened, the contestant gains more information about distribution of probable reward in his/her own box. In the beginning of the game, the rewards are highly distributed and positively skewed. Throughout the game, the distribution and skewness are reduced as the boxes are opened, and the distribution becomes perfectly symmetrical in the final round of the game. Another important thing that provides contestants with advantages in regard to statistical characteristic of the game is that if all of the unopened boxes exactly have the same subjective probability in order to win any of the rewards left, then a positive expected return occurs that requires contestants to stay in the game throughout the rounds (Andersen et al., 2008). Andersen et al. (2014); this might cause participants who avoid risks to stay in the game throughout the rounds, and therefore the box owned by the contestant has an option value in the next rounds. In other words, saying "No Deal" in previous rounds provides contestant with option for offering a higher amount in the next rounds. Table 2 includes rewards won on the basis of countries, number of rounds in which the offer was accepted, and statistics on the ratio of accepted offer to the expected value of unopened boxes.

Table 2. Statistics of contestant's decisions

\begin{tabular}{lcccc}
\hline & Mean & Standard Dev. & Min & Max \\
\hline Turkey (N=39) & & & & \\
Round that accepting the offer & 6.59 & 0.5 & 6 & 7 \\
The Amount of Accepted Offer/E.V. & 0.48 & 0.26 & 0.23 & 1.42 \\
Amount Won & 52.597 & 26.005 & 10.067 & 87.919 \\
USA (N=11) & & & & \\
Round that accepting the offer & 7 & 1.67 & 4 & 9 \\
The Amount of Accepted Offer/E.V. & 0.87 & 0.2 & 0.5 & 1.09 \\
Amount Won & 80.333 & 88.563 & 7 & 252 \\
Indonesia (N=31) & & & & \\
Round that accepting the offer & 7.28 & 1.94 & 2 & 9 \\
The Amount of Accepted Offer/E.V. & 0.61 & 0.29 & 0.07 & 1.02 \\
Amount Won & 8.011 & 15.091 & 95 & 69.419 \\
Australia (N=20) & & & & \\
Round that accepting the offer & 7.14 & 1.83 & 3 & 9 \\
The Amount of Accepted Offer/E.V. & 0.85 & 0.13 & 0.58 & 1 \\
Amount Won & 25.431 & 18.637 & 3.6 & 68.4 \\
\hline
\end{tabular}


Even if the contestants do not exactly know in advance the offers of the bank, the bank appears to act consistently within a clear pattern. Offers are very lower than the expected value of probable rewards in the early rounds of the game. As the game progresses, the difference between the expected value and the offer is reduced (Blavatskyy \& Pogrebna, 2007). The bank's behavioral pattern has 4 basic simple rules (Post et al., 2008, p. 43);

1) An offer of the bank is based on the value of unopened boxes.

2) While the rate of bank's offers to the mean of remained boxes is low in early rounds, this rate is increased in the next rounds.

3) The bank's offers are not informative in order to identify the amount contained in the box of contestant. Only an independent observer knows the distribution.

4) The bank offers higher amounts to contestants that lose the game in percentage of remaining boxes and becomes generous.

The table below provides offers received by contestants of our sample in each round and the statistics on expected values with respect to boxes opened.

Table 3. Bank offers and expected value of remaining boxes

\begin{tabular}{|c|c|c|c|c|c|c|c|c|c|}
\hline \multicolumn{2}{|c|}{26 Boxes Vers. } & \multicolumn{3}{|c|}{ Bank Offers } & \multicolumn{5}{|c|}{ Expected Value of Remaining Boxes } \\
\hline Round & $\mathrm{N}$ & Mean & St.Dev. & Min & Max & Mean & St.Dev. & Min & Max \\
\hline 1 & 62 & 7.433 & 18.352 & 183 & 139 & 34.948 & 56.213 & 2.22 & 305.652 \\
\hline 2 & 62 & 9.833 & 18.253 & 227 & 120 & 33.568 & 52.97 & 1.589 & 274.175 \\
\hline 3 & 62 & 10.26 & 25.152 & 351 & 195 & 26.516 & 51.787 & 1.565 & 373.702 \\
\hline 4 & 62 & 12.253 & 29.328 & 250 & 223 & 26.074 & 53.334 & 291 & 384.466 \\
\hline 5 & 61 & 15.894 & 37.184 & 146 & 261 & 26.846 & 52.388 & 354 & 345.95 \\
\hline 6 & 56 & 18.314 & 45.309 & 73 & 305 & 26.919 & 62.122 & 162 & 415.04 \\
\hline 7 & 48 & 23.307 & 62.291 & 11 & 410 & 32.229 & 81.188 & 15 & 518.75 \\
\hline 8 & 38 & 31.78 & 104.152 & 15 & 603 & 38.73 & 116.13 & 19 & 666.667 \\
\hline 9 & 33 & 24.811 & 73.906 & 2 & 416 & 31.219 & 88.325 & 2 & 501 \\
\hline \multicolumn{2}{|c|}{24 Boxes Vers. } & \multicolumn{4}{|c|}{ Bank Offers } & \multicolumn{4}{|c|}{ Expected Value of Remaining Boxes } \\
\hline 1 & 39 & 12.562 & 6.892 & 2.685 & 33.557 & 78.651 & 17.271 & 44.59 & 119.782 \\
\hline 2 & 39 & 20.151 & 11.594 & 4.698 & 50.336 & 81.341 & 21.99 & 49.578 & 140.14 \\
\hline 3 & 39 & 26.553 & 13.613 & 8.725 & 57.047 & 86.486 & 27.24 & 31.566 & 159.546 \\
\hline 4 & 39 & 33.298 & 16.762 & 7.383 & 73.826 & 92.882 & 34.441 & 13.567 & 194.658 \\
\hline 5 & 39 & 36.878 & 25.334 & 6.04 & 97.315 & 101.196 & 54.699 & 6.829 & 266.577 \\
\hline 6 & 39 & 45.571 & 36.847 & 101 & 174.497 & 112.175 & 68.418 & 169 & 348.993 \\
\hline 7 & 26 & 53.425 & 41.802 & 134 & 154.362 & 113.742 & 94.215 & 135 & 362.416 \\
\hline
\end{tabular}

\section{Calculation of the Degree of Relative Risk Aversion of Contestants by Bounds Approach}

The risk aversion is a concept related to individual's attitude towards risk. Simply, the risk aversion is defined as "choosing the less risky alternative by an individual compared to choices with comparable returns" (Taşdemir, 2007, p. 311). The limits of the degree of RAA can be calculated based on contestant decision to "accept" or "reject" the bank's offer in each round. In other words, when a contestant rejects the bank's offer, this indicates the upper limit of coefficient of risk aversion. When the contestant accepts the offer, this indicates the lower limit. The upper and lower limit of each contestant can be calculated based on this logic. First, the coefficient of RRA is calculated at the point where the contestant remains unresponsive to either accepting or rejecting the offer in each round of the game. If the contestant accepts the offer in any of the rounds, it is considered that the RRA degree of the contestant is higher than the offer, if the contestant rejects the offer then the RRA degree of the contestant is lower than the offer. In this way, bounds calculated by rounds are combined to achieve a point estimation for the RRA degree of the contestant. In the formulation, contestants are represented by $\mathrm{i}(\mathrm{i}=1 \ldots \ldots . \mathrm{N})$ and the rounds of the game are represented by $r(r=1 \ldots \ldots .10)$. $R$ represent the number of rounds in which the game ends, i.e., the contestant accepts the offer ( $\mathrm{R}=10$ if the contestant rejects all of the offers). W represents the initial wealth level of the contestant. Rewards left for a given round are represented by $x_{r}$, and the number of rounds left are represented by $n_{r}$. For a determined $r(r=1 \ldots \ldots .9)$, it is subset of $n_{r+1}$ that is one of the elements of $\mathrm{x}_{\mathrm{r}+1} \mathrm{x}_{\mathrm{r}}$. Similarly, sum of all subsets is represented by $\mathrm{x}_{\left(\mathrm{x}_{\mathrm{r}}\right)}$. Choices for the coefficient of RRA $y$ are modelled 
using the utility function CRRA;

$$
u(x / y, W) \equiv \frac{(x+W)^{1-y}}{1-y}
$$

The expected utility of rejecting the bank's offer for determined rewards left (xr) is calculated as follows. The statistical distribution of $\mathrm{xr}+1$ is known for a specific $\mathrm{xr}$ :

$$
\operatorname{Pr}\left[x_{r+1}=y / x_{r}\right]=\left(\begin{array}{c}
\mathrm{n}_{\left(\mathrm{x}_{\mathrm{r}}\right)} \\
\mathrm{n}_{\left(\mathrm{x}_{\mathrm{r}+1)}\right)}
\end{array}\right)^{-1}
$$

So, the expected utility of rejecting the offer for any $r(r=1 \ldots . . .9)$ :

$$
g\left(x_{r}, y, W, b\right) \equiv \sum_{\mathrm{zEX}(\mathrm{y})} \max \{u(b(y) / y, W), g(y, y, W, b)\} \times\left(\begin{array}{l}
\mathrm{n}(\mathrm{y}) \\
\mathrm{n}(\mathrm{z})
\end{array}\right)^{-1}
$$

Since there is only one box left which is the contestant's own box in the tenth round, the bank's offer equals to the amount contained in the contestant's box $\left(b\left(\mathrm{x}_{10}\right)=\mathrm{x}_{10}\right)$ and there is now nothing to decide by the contestant:

$$
g\left(x_{10, y}, W, b\right) \equiv u\left(x_{10} / y, W\right)
$$

For any determined round (r) and the contestant (i), the critical RRA value at where the contestant remains indifferent to accepting (deal) or rejecting (no deal) the offer is calculated as follows:

$$
\widehat{y}_{i, r}(W, b) \equiv\left\{y: g\left(x_{i, r}, y, W, b\right)=u\left(b\left(x_{i, r}\right) / y, r\right)\right\}
$$

If a contestant accepts the bank's offer, this means the RRA coefficient of that contestant is higher than the critical value at where the contestant remained indifferent. Consequently, the critical value of the individual is the lower limit of RRA coefficient $\left(\widehat{y}_{i}^{\mathrm{L}}(\mathrm{W}, \mathrm{b}) \equiv \widehat{\mathrm{y}}_{\mathrm{i}, \mathrm{R}}(\mathrm{W}, \mathrm{b})\right)$. Similarly, the RRA coefficient of the contestant is lower than the critical value $\widehat{y}_{i, r}(W, b)$ in previous rounds $(r \leq R-1)$. As the game progresses, given that the bank becomes more generous, the lowest upper limit is usually reached in the round prior to the round in which the offer is accepted. Finally, the arithmetic mean of these two bounds is calculated to obtain the RRA coefficient.

$$
\widehat{y}_{i, r}(W, b) \equiv \frac{1}{2}\left(\widehat{y}_{\mathrm{i}}^{\mathrm{L}}(W, b)+\left(\widehat{y}_{\mathrm{i}}^{\mathrm{U}}(W, b)\right)\right.
$$

It is necessary to determine wealth level of individuals for estimating the degree of relative risk aversion. Since the data that was acquired from the game did not provide any information about income level of individuals, estimates were based on a variety of income levels. In previous studies, because " 0 " and "annual minimum wage" were often used as income level of individuals, the degree of risk aversion of contestants was calculated based on these two values in this study.

Table 4. RRA Coefficients of sample

\begin{tabular}{lcccc}
\hline & Mean & Std. Dev. & Min & Max \\
\hline All Sample (N=73) & & & & \\
\hline RRA (W=0) & 1.467 & 8.954 & -0.026 & 79.912 \\
RRA (W=Annual Min. Wage) & 2.075 & 6.487 & 0 & 39.02 \\
Turkey (N=27) & & & & \\
\hline RRA (W=0) & 3.547 & 15.26 & 0.245 & 79.912 \\
RRA (W=Annual Min. Wage) & 2.302 & 7.34 & 0.354 & 39.02 \\
USA (N=6) & & & & \\
\hline RRA (W=0) & 0.182 & 0.18 & -0.026 & 0.367 \\
RRA (W=Annual Min. Wage) & 6.737 & 12.2 & 0.081 & 39 \\
Indonesia (N=26) & & & & \\
\hline RRA (W=0) & 0.289 & 0.37 & -0.017 & 1.722 \\
RRA (W=Annual Min. Wage) & 1.626 & 4.23 & 0 & 21.956 \\
Australia (N=14) & & & & \\
\hline RRA (W=0) & 0.194 & 0.14 & 0.015 & 0.469 \\
RRA (W=Annual Min. Wage) & 0.475 & 0.26 & 0.039 & 0.864 \\
\hline
\end{tabular}

* In calculation of RRA degree, monthly minimum wage of respective country for the relevant period was obtained from the database of OECD as annual minimum wage levels, and it was used on the basis of years. In this respect, it is 14.304 TL for Turkey; $\$ 14.441$ for the USA; 26.400.000 Rupee for Indonesia, and 29.343 Australian dollars for Australia.

Table 4 provides statistics on the degree of relative risk aversion calculated based on " 0 " and "annual minimum wage" both by the entire sample and by subgroups of countries. Accordingly, the degree of risk aversion among 
participants was very variable in support of previous relevant studies. When evaluating the entire sample, the mean of degree of risk aversion was increased as the income was increased. However, from perspective of country subgroups, the mean of degree of risk aversion of Turkish contestants was reduced as the income was increased, and the mean of degree of risk aversion of other countries' contestants was increased with the increased income. It is considered that personality traits, a variety of experienced emotional factors or socioeconomic/demographic characteristics of individual may have an influence on individual differences in the degree of risk aversion. The differences between countries might be due to cultural factors or differences in wealth level.

\section{Emotions and Decision-Making}

A variety of contributions made to investigate the relationship between emotions and decision-making indicate different perspectives of such mutual interaction. In other words, the relationship between emotions and decision-making is not as simple as it is considered. The studies suggest that emotions experienced by us in the past and emotions that we want to experience or avoid in the future have an influence on decisions we make in addition to current mood. Schwarz (2000) categorized such mutual interaction between emotions and decision-making as "affection at the time of decision", "affection after decision", "expected affection", and "memories of past affections". For example, it is established in regard to "affection at the time of decision" that emotional states have influence on decision-making through affecting the strategy of individual for processing information, and as a result of this, individuals in a happy mood overestimate the probability of positive outcomes and events and underestimate the probability of negative outcomes and events. There are different ways for the influence of current mood on decisions. For example, there are significant differences between happy individuals and sad individuals in terms of level of confidence in dataset that exists at the stage of decision making and importance placed on details. In regard to "affection after decision", it can be suggested that positive or negative outcomes of a decision made may significantly influence emotions of decision maker; and feelings such as regret and disappointment may set a good example of such interaction. Studies (Bell, 1982, 1985; Loomes \& Sugden, 1982) indicate that current decisions are shaped to avoid experiencing major feelings (regret and disappointment), or re-experience certain feelings in the future. March (1978) reports that any decisions are based on estimation of future emotions. Lastly, it was suggested that emotions experienced in the past had an influence on the decision that are made today, and that recalling memories of such emotions from the memory resulted in making non-optimal decisions (Schwarz, 2000).

At this point, it is important to highlight the distinction between the mood and emotions. There are many characteristics that differentiate these two factors from each other. For example, emotions are short-lived, more intense, and typically occur as reaction to specific conditions (Capra, 2004). The mood, on the other hand, has a longer effect, is less intense, and cannot be based on a specific event. Some emotions come through distinct facial expressions but not the mood (Ekman, 1994).

\subsection{Emotions and Risk Aversion}

Strong emotions are often held responsible for decisions that are made under risk and uncertainty (Kugler et al., 2012). As pointed out by a growing literature, emotions affect the risk assessments in a systematic and foreseeable manner (Druckman \& McDermott, 2008). Studies performed on emotions and risk assessments are based on the study by Bower (1981). In this study, Bower suggested a relationship between the mood and the memory, and that individuals in a bad mood were very likely to recall adverse events, and individuals in a good mood would readily recall positive experience. Johnson and Tversky (1983) implemented such logic into debate that specific emotions might affect the risk assessment and found that positive emotions triggered optimistic risk assessments, and negative emotions resulted in negative risk assessment.

The primary focus of economy, psychology and neuroscience research is the mechanism on which decisions made under risk is based. The traditional approach adopted by economy is that a utility function applies that indicates individual preferences and has a nature of expected utility. Based on this hypothesis, (Nguyen \& Noussair, 2014, p. 300);

1) Concavity: Indicates the choice of relatively safe chance of games

2) Convexity: Indicates the choice of relatively risky chance of games.

People evaluate objective characteristics of alternatives, such as expected return, in a subjective manner (Kahneman \& Tversky, 1979), and emotions play an important role in understanding the influence of such subjective evaluation. Researchers suggest that emotions play an active role in a number of ways of making decisions on contrary to traditional thought of psychology and economy, and emphasize that such endogenous 
role of emotions in decision-making process is as important as value of expectations. Therefore, neuro-economists underline that mutual interaction between emotions and decision-making can be profitably investigated in studies in an environment that contains risk and uncertainty (Rangel et al., 2008). Studies performed by neuroscientist identified that making decisions at risk had psychological associations. Similarly, psychologists and behavioral economists emphasize that emotions, such as happiness and fear, are directive for decisions made by individuals under risk conditions (Forgas, 1995; Loewenstein \& Lehrer, 2003).

Fessler et al. (2004) suggest that most of the theories for association between the risk taking and active emotions are revealed either as a reaction to one of two approaches or is derived from it. They are:

1) Mood-Maintenance Hypothesis (Isen \& Patrick, 1983): Individuals in positive mood do not want to take risk, because their positive mood will be impaired if they experience a loss. Thus, individuals in negative mood want to take risk to improve their negative mood.

2) Affective Generalization Hypothesis (Johnson \& Tversky, 1983): They are interested in the role of emotion in assessment of probabilities. They suggest that negative emotions result in a more pessimistic risk assessment and positive emotions result in a more optimistic risk assessment.

Previous relevant studies have been focused on the influence of either overall positive or negative emotions (Isen et al., 1982; Johnson \& Tversky, 1983; Shwarz \& Klore, 1983; Isen, 1997; Capra, 2004; Simonsohn, 2007) or on the role of specific emotions such as regret, disappointment, fear, and happiness (Loomes \& Sugden, 1982; Bell, 1985; Larrick \& Boles, 1995;Connoly \& Zeelenberg, 2002). However, many recent studies performed in psychology in particular underline that studying individual emotions was more important than studying general positive and negative moods (De Steno et al., 2000; Lerner \& Keltner, 2001; Druckman \& McDermott, 2008; Kugler et al., 2012).

Studies investigating the effect of specific emotions on risk assessment have found that sad individuals tend to see the risk for adverse events such as cancer higher than happy individuals (Druckman \& McDermott, 2008, p. 300). Different emotions are experienced as a reaction to different cognitive appraisal of a state, and such appraisal produces distinct cognitive and motivational tendencies that affect reasoning and decision-making (Kugler et al., 2012). For example, both anger and fear have a negative value and very different appraisal models in relation to dimensions of risk assessment (Lerner \& Tiedens, 2006). Smith and Ellsworth (1985) and Lerner and Keltner (2001) indicate that anger gives weight to individual control and has high-precision assessment pattern, on contrary the fear has low-precision assessment pattern and gives weight to situational control. Lerner and Keltner (2001) report that angry people relatively want to take risk and have optimistic risk assessment. On contrary, assessments of people in fear tend to low-precision emphasis, therefore events are perceived as frightening and unforeseeable. As a result, people in fear have a higher perception for risk and display risk aversion behaviors (Sitkin \& Weingart, 1995; Tsai \& Young, 2010). Raghunathan and Pham (1999) suggest that anxiety and sadness have similarly maladaptive effects, and anxious individuals avoid risks more and unhappy individuals seek for more risks. According to Tiedens and Linton (2001), as anger, the happiness is seen with feeling of precision (feeling of understanding what is happening in current situation and ability to predict what will happen in the future). As a result more happiness results in taking more risks. Lerner and Keltner (2001) also found that happiness resulted in taking more risks.

\subsection{Emotion Recognition from Facial Expressions}

With advances in information technologies, human-computer joint studies have started to draw more attention. People usually estimate their emotional state from language used by them, their voices, gesture, and appearance (Hyoun et al., 2003, p. 2890). An emotion is a prototypical form of facial expressions. For example, emotion of fear is characterized by specific facial expressions. Eyebrows are raised and lowered together, the lower lip is stretched, the lips are extended backwards, and the eyes are opened widely (Ekman \& Friesen, 1975). Accordingly, there are various researches on recognition of emotions from facial expressions. These researches are based on optical flow analyses, principal component analyses (PCA), local feature analyses (LFA), linear discriminant analyses (LDA), independent component analyses (ICA), local component analyses (LCA), and Gabor wavelet expression method. When compared with other methods by which biological reactions are measured in relation to emotion recognition methods (skin conductance reaction measurement, magnetic resonance imaging), face reading programs have an advantage to display psychological reactions directly in specific emotions. For example, Noldus Facereader (Noldus et al., 2005) analyzes facial expressions and measures compatibility with 6 basic universal emotions catalogued by Ekman (2007). These emotions include fear, happiness, anger, disgust, surprise and sadness. These emotions are universally defined because the same facial expressions are associated with the same emotions in any of the cultures. All primates have common 
expressions. In this study, the demo version of Micsrosoft Project Oxford Emotion Recognition (Note 2) software was used. This software analyzes facial expressions and, differently from Noldus Facereader software, measures compatibility with 8 basic universal emotions. These emotions include anger, contempt, disgust, fear, happiness, neutral, surprise, and sadness.

\section{Discussion}

The study initially started with determination of whether emotions experienced by contestants significantly varied among different rounds of the game. Emotions experienced by contestants were identified based on the pictures of contestants taken immediately before making a decision on the bank's offer in a round. The Appendix I and appendix II show differences in emotions of participants between rounds. Since there are two different versions of datasets for the DoND game, contestants played in the version with 26 boxes and contestants played in the version with 24 boxes are indicated in separate tables. Accordingly, there were no significant differences between different rounds for contestants played in the version of 26 boxes and the mean of emotional levels. However, the mean of almost all of the 8 emotions reached the highest level especially in last rounds of the game (the 5th, 6th, 7th, and 8th rounds). In Turkish version with 24 boxes, statistically significant differences were found between the 1st and 6th rounds in terms of happiness and neutral So, the mean of emotion of happiness was higher in the 1st round than that of the 6th round, and the mean of emotion of neutral was low. As it was no possible to predict the result of the game in the first round, generally the contestants appeared happy in that round. In the last rounds, the minimum and maximum amounts to win become somewhat apparent, resulting in increased excitement in the game. As required by importance of decisions to make, happiness of contestants is replaced with neutral during the last rounds. It is not surprising that there were no significant differences between other emotions by rounds. As the game is fully based on chance, different combinations relating to distribution of unopened boxes have an effect on timing of revealing different emotions.

In the relevant literature, the relationship between emotions and risk aversion is established using different methods (financial decisions measured by tasks). In that study, the emotions were exogenous. But in the present study, the emotions were endogenous. In other words, the emotions that might have influence on participants' behavior in the game and the degree of risk aversion result from the game's own dynamics. For example, the substantiality and distribution of amounts contained in unopened boxes in the last round, opening of boxes with very high amount or very small amount, successive opening of boxes with very high amount or very small amount, and the round in which the boxes are opened make contestants experience various emotions. In the course of the game, the contestants were classified as unlucky, normal and lucky based on variables including "the amount of expected value", "standard deviation in the expected value" and "the ratio of boxes with high amount among unopened boxes" for each round from the hypothesis that statistical distribution of opened and remained boxes forced contestants to experience various emotions. In this classification that addressed each country individually, the frequency distribution of values of abovementioned variables in each round was considered. For example, according to frequency distribution of expected values of contestants in the 1st round of Turkish version of the game, those that feel into the 33\% lowest amount of expected value were classified as "unlucky", and those that feel into the $\% 33$ highest amount of expected value were classified as "lucky", and those in between were classified as "normal". This approach was implemented for each round of the game on the basis of countries and for three variables mentioned above.

Based on this, the first analysis divided contestants into 9 different groups of chance according to the "amount of expected value" and "standard deviation in the expected value" and it was investigated whether there were significant differences between these groups of chance by rounds in terms of experienced emotions. From the perspective of participants, it was desirable that first the expected value should be high and then the standard deviation in this expected value should be low. Low standard deviation in the expected value means that the boxes left contain amounts that are closer to each other. So, if the participant has the highest expected value of $33 \%$ but also the standard deviation in this expected value falls into the lowest group of 33\%, the luckiest groups is represented by (1). From the logic, the unluckiest group is consisted of participants (9) with the lowest expected value but also the highest standard deviation in this expected value (9). In this classification, groups 1 , 2, 4 and 6 both had the highest expected value and the lowest standard deviation in this expected value. Groups 3 , $5,7,8$ and 9 had lower expected value and higher standard deviation that other groups. Table 5 shows the results of analyses. 
Table 5. The differences occur in terms of the level of emotion between luck groups

\begin{tabular}{|c|c|c|c|c|c|c|c|}
\hline \multirow{2}{*}{ Dependent Variable } & \multirow{2}{*}{$\begin{array}{c}\text { (I) } \\
\text { Group }\end{array}$} & \multirow{2}{*}{ (J) Group } & \multirow{2}{*}{$\begin{array}{c}\text { Mean Difference } \\
(\mathrm{I}-\mathrm{J})\end{array}$} & \multirow{2}{*}{ Std. Error } & \multirow{2}{*}{ Sig. } & \multicolumn{2}{|c|}{$95 \%$ Confidence Interval } \\
\hline & & & & & & Lower Bound & Upper Bound \\
\hline \multicolumn{8}{|c|}{ Tours of the Bank's offer was rejected } \\
\hline Happiness & 3 & 5 & ,27174* & 07913 & ,019 &, 0251 & ,5184 \\
\hline ANOVA & 9 & 5 & & & & & \\
\hline $\begin{array}{c}F=2,346 \\
\mathrm{Sig}=0,018\end{array}$ & & & ,21748* & ,06906 & ,045 &, 0022 & ,4327 \\
\hline Neutral & 3 & 5 &,$- 25664 *$ & 07179 & ,012 &,- 4804 &,- 0329 \\
\hline ANOVA & 9 & 5 & & & & & \\
\hline $\begin{array}{c}F=2,973 ; \\
\mathrm{Sig}=0,003\end{array}$ & & &,$- 22978^{*}$ & ,06266 &, 008 &,- 4251 &,- 0345 \\
\hline \multicolumn{8}{|c|}{ Tours of the Bank's offer was accepted } \\
\hline Disgust & 1 & 9 &,$- 01628^{*}$ & ,00453 & ,017 &,- 0307 &,- 0018 \\
\hline ANOVA & 2 & 9 &,$- 01413^{*}$ & 00375 &, 011 &,- 0261 &,- 0022 \\
\hline $\mathrm{F}=2,702$ & 4 & 9 &,$- 01619^{*}$ & 00415 & ,007 &,- 0294 &,- 0030 \\
\hline $\mathrm{Sig}=0,021$ & 5 & 9 &,$- 01503^{*}$ & 00377 & ,006 &,- 0270 &,- 0030 \\
\hline Scheffe & 7 & 9 &,$- 01565^{*}$ &, 00430 & ,015 &,- 0293 &,- 0020 \\
\hline $\begin{array}{l}\text { Neutral } \\
\text { ANOVA } \\
\mathrm{F}=1,451 ;\end{array}$ & 1 & 5 &,$- 57443^{*}$ & ,10694 & ,005 &,- 9997 &,- 1492 \\
\hline $\begin{array}{c}\text { Sig }=0,211 \\
\text { Tamhane }\end{array}$ & 9 & 5 &,$- 55155^{*}$ & ,10923 & ,007 &,- 9791 &,- 1240 \\
\hline Happiness & & & & & & & \\
\hline $\begin{array}{l}\text { ANOVA } \\
\mathrm{F}=1,870\end{array}$ & 1 & 5 &, $66835^{*}$ & ,11051 & ,002 & ,2289 & 1,1078 \\
\hline $\begin{array}{c}\mathrm{Sig}=0,098 \\
\text { Tamhane }\end{array}$ & 9 & 5 & ,62814* & ,11067 & ,003 &, 1887 & 1,0675 \\
\hline
\end{tabular}

*Group 1 had high expected value and standard deviation; group 2 had mean expected value and low standard deviation; group 3 had low expected value and low standard deviation; group 4 had high expected value and mean standard deviation; group 5 had high expected value and high standard deviation; group 6 had mean expected value and mean standard deviation; group 7 had mean expected value and high standard deviation; group 8 had low expected value and mean standard deviation; group 9 had low expected value and high standard deviation.

So, the mean of happiness in group 5 was lower than that of groups 3 and 9 in rounds where the bank's offer was rejected. The characteristic of group 5 is that the amount of expected value was high and standard deviation was also high. This means that there were only few boxes with high amount and there were a lot of boxes with small amount among boxes left. From perspective of the contestant, this might be due to higher cost opportunity than boxes 3 and 9 . The distribution of emotion of neutral among these groups of chance supports this judgment. The emotion of neutral in group 5 was higher than two other groups. This may be interpreted that the decision made was critical to the contestant.

When evaluated by the rounds where the bank's offer was accepted, the mean of emotion of disgust of the unluckiest group was especially higher than groups that had high expected value. The group 1 is very likely to end the game with a high amount. The group 9 had no chance to win the game with a high amount. The group 5 had a very little chance to win the game with a high amount. The mean of emotion of neutral in this group was higher than that of two other groups, and the mean of emotion of happiness was lower than that of two others, this might be because the decision to make was critical.

Then, the multiple regression analysis was performed to determine the influence of emotions of contestants in the groups 1,2, 4 and 6 on the degree of risk aversion. The analysis was performed for individual rounds in which the offer was rejected or accepted. The dependent variable was RRA bounds in rounds in which the offer was rejected and was the degree of RRA in rounds in which the offer was accepted. The models were not found significant at the fixed level of income, but both of the models were significant at the level of minimum wage. The results of analysis are provided in tables below. So, the first model accounts for $7 \%$ of variance of RRA bounds value. The most important explanatory variable was the emotion of surprise. The model 2 accounts for nearly half of the variance of degree of risk aversion. The most important explanatory variables of this model appear to be contempt and sadness. These two emotions were positively correlated with the risk aversion.

Another significant dynamic that put endogenous emotion on contestants during the course of the game was 
opening of boxes with a very high and a very small amount. Opening of one of the boxes with a high amount means to the contestant that the expected value was dramatically reduced and the possibility of completing the game with a small amount was increased. Opening of any of the boxes with a small amount means that the expected value and the possibility of completing the game with a high amount was increased.

Table 6. Effects of emotions on risk aversion

\begin{tabular}{|c|c|c|c|c|c|}
\hline & & & & & \\
\hline & Coefficient & Standard Error & Beta & t-statistic & p-value \\
\hline (Constant) & 1.060 & .109 & & 9.700 & .000 \\
\hline Anger & -.145 & 1.210 & -.008 & -.120 & .905 \\
\hline Contempt & .685 & 1.302 & .034 & .526 & .599 \\
\hline Disgust & -3.406 & 2.253 & -.103 & -1.511 & .132 \\
\hline Fear & 11.787 & 12.712 & .062 & .927 & .355 \\
\hline Neutral & -.047 & .194 & -.015 & -.242 & .809 \\
\hline Sadness & .938 & 1.048 & .057 & .895 & .372 \\
\hline Surprise & 2.057 & .504 & .273 & 4.083 & .000 \\
\hline R-sq & 0,09 & & & & \\
\hline Adj. R-sq.0,07 & 0,07 & & & & \\
\hline \multicolumn{6}{|c|}{ Model 2. Dependent Variable RRA Coefficients $\quad(\mathrm{W}=$ Annual min. wage) $(\mathrm{F}=3,618 ;$ Sig. $=0,01)$} \\
\hline & Coefficient & Standard Error & Beta & t-statistic & p-value \\
\hline (Constant) & .583 & .117 & & 4.992 & .000 \\
\hline Anger & 59.344 & 56.400 & .424 & 1.052 & .305 \\
\hline Contempt & 7.450 & 2.248 & .509 & 3.313 & .003 \\
\hline Disgust & -60.454 & 67.555 & -.396 & -.895 & .381 \\
\hline Fear & -72.406 & 54.005 & -.427 & -1.341 & .195 \\
\hline Neutral & -.463 & .381 & -.291 & -1.214 & .239 \\
\hline Sadness & 85.487 & 30.904 & .750 & 2.766 & .012 \\
\hline Surprise & 8.666 & 12.087 & .218 & .717 & .482 \\
\hline $\mathrm{R}$-sq & 0,55 & & & & \\
\hline Adj. R-sq.0,07 & 0,40 & & & & \\
\hline
\end{tabular}

* Excluded variable in model 1 and model 2: happiness.

The table below shows the differences in emotions experienced by contestants after boxes with a very high amount, which are often indicated in red in the tree of money, and the boxes with a very small amount located to the left of the display were opened. So, the mean of emotions of anger, disgust and neutral experienced by contestants when the boxes with high amount were opened was higher than when the boxes with small amount were opened; and the happiness was higher when the boxes with small amount were opened. Based on the emotions of contestants experienced when opening of boxes with high amount, the last phase of the analysis calculated the ratio of boxes with high amount among unopened boxes for each round, and the groups of chance were identified for each round based on the frequency distribution. So, the limit for boxes with high amount among boxes left was $17 \%$ for the unlucky group (1); it was $18 \%$ to $33 \%$ for the normal group, and it was $34 \%$ to $100 \%$ for the lucky group. Based on the distribution of boxes in the early rounds of the game, this analysis used data of the 5th, 6th, 7th, 8th and 9th rounds because the power of estimate was generally low for the result of the game. Then differences in levels of emotion were determined between the rounds in which the offer was rejected or accepted individually for groups of chance. Table 8 provides the results of analysis.

Table 7. The differences occur in terms of emotions between very high and very low amount boxes

\begin{tabular}{lccccc}
\hline F=18,798; Sig. =0,00; Sig. 2 tailed.=0,01 & & & & \\
\cline { 2 - 6 } & Grup & $\mathrm{N}$ & Mean & Std. Deviation & Std. Error Mean \\
\cline { 2 - 6 } Anger & High Amount & 284 &, 0116 &, 06065 &, 00360 \\
& Low Amount & 257 &, 0023 &, 00787 &, 00049 \\
\hline \multirow{2}{*}{ F=22,605; Sig. =0,00; Sig. 2 tailed.=0,00 } & & & &, 00465 \\
\hline \multirow{2}{*}{ Disgust } & High Amount & 284 &, 0174 &, 07835 &, 00061 \\
\hline \multirow{2}{*}{ F=0,275; Sig. =0,60; Sig. 2 tailed.=0,00 } & Low Amount & 257 &, 0039 &, 00984 &, 02413 \\
\hline \multirow{2}{*}{ Happiness } & High Amount & 284 &, 4080 &, 40659 &, 02503 \\
& Low Amount & 257 &, 5282 &, 40128 & \\
\hline
\end{tabular}




\begin{tabular}{cccccc}
\hline $\mathrm{F}=8,834 ;$ Sig. $=0,00$; Sig. 2 tailed. $=0,00$ & & & \\
\hline \multirow{2}{*}{ Neutral } & High Amount & 284 &, 4910 &, 38790 &, 02302 \\
& Low Amount & 257 &, 3838 &, 35980 &, 02244 \\
\hline
\end{tabular}

In analyses performed for the unlucky group, there were no differences in levels of emotion between the rounds in which the offer was rejected or accepted. In the group where the ratio of boxes with high amount was $18 \%$ to $33 \%$, the mean of anger was lower, the mean of happiness was higher, the mean of sadness was lower and the mean of neutral was lower in the rounds in which the offer was accepted compared to the rounds in which the offer was rejected.

Table 8. The differences occur in terms of emotions between the tours that bank offer accepted and rejected on the basis of chance groups

\begin{tabular}{|c|c|c|c|c|c|}
\hline \multicolumn{6}{|c|}{ Ratio of boxes with high amount among unopened boxes: $\% 18-33$} \\
\hline \multicolumn{6}{|c|}{$\mathrm{F}=9,529 ;$ Sig. $=0,00 ;$ Sig. 2 tailed. $=0,00$} \\
\hline \multirow{3}{*}{ Anger } & Group & $\mathrm{N}$ & Mean & Std. Deviation & Std. Error Mean \\
\hline & Reject & 51 & .0029 & .00500 & .00070 \\
\hline & Accept & 12 & .0004 & .00091 & .00026 \\
\hline \multicolumn{6}{|c|}{$\mathrm{F}=0,874 ;$ Sig. $=0,35 ;$ Sig. 2 tailed. $=0,00$} \\
\hline \multirow{2}{*}{ Happiness } & Reject & 51 & .3648 & .36838 & .05158 \\
\hline & Accept & 12 & .7519 & .36906 & .10654 \\
\hline \multicolumn{6}{|c|}{$\mathrm{F}=8,918 ;$ Sig. $=0,00 ;$ Sig. 2 tailed. $=0,00$} \\
\hline \multirow{2}{*}{ Sadness } & Reject & 51 & .0277 & .05099 & .00714 \\
\hline & Accept & 12 & .0015 & .00281 & .00081 \\
\hline \multicolumn{6}{|c|}{$\mathrm{F}=7,748 ;$ Sig. $=0,00 ;$ Sig. 2 tailed. $=0,00$} \\
\hline \multirow{2}{*}{ Neutral } & Reject & 51 & .5187 & .34985 & .04899 \\
\hline & Accept & 12 & .1674 & .27267 & .07871 \\
\hline \multicolumn{6}{|c|}{ Ratio of boxes with high amount among unopened boxes: $\% 34-100$} \\
\hline \multicolumn{6}{|c|}{$\mathrm{F}=6,114 ;$ Sig. $=0,01 ;$ Sig. 2 tailed $.=0,03$} \\
\hline \multirow{3}{*}{ Contempt } & Group & $\mathrm{N}$ & Mean & Std. Deviation & Std. Error Mean \\
\hline & Reject & 54 & .0116 & .02108 & .00287 \\
\hline & Accept & 22 & .0049 & .00548 & .00117 \\
\hline \multicolumn{6}{|c|}{$\mathrm{F}=8,665 ;$ Sig. $=0,00 ;$ Sig. 2 tailed. $=0,02$} \\
\hline \multirow{2}{*}{ Surprise } & Reject & 54 & .0288 & .08158 & .01110 \\
\hline & Accept & 22 & .0025 & .00794 & .00169 \\
\hline
\end{tabular}

In the group where the ratio of boxes with high amount was $34 \%$ to $100 \%$, the mean of contempt and surprise was lower in the rounds in which the offer was accepted compared to the rounds in which the offer was rejected.

\section{Conclusion}

This is one of the first studies that investigated the influence of emotions estimated using the face reading method on the risk aversion based on the game of DoND. In this game, emotions are endogenously revealed based on the distribution of opened boxes and unopened boxes during the course of the game. Therefore, it is unlikely that especially strong emotions, such as anger, fear and sadness, are severely revealed during the normal course of this television show. Despite this, the results of this study indicate strong evidence that emotions may have an influence on the decisions made and the level of risk aversion. Based on the results, it can be suggested that the anger, happiness, sadness, neutral, contempt and surprise may be correlated with the risk aversion. These results are consistent with the results of the first study (Nguyen \& Noussair, 2014) that investigated the relationship between the emotions identified using the face reading method and the risk aversion.

\section{References}

Andersen, S., Harrison, G. W., Lau, M. I., \& Rutström, E. E. (2014). Dual criteria decisions. Journal of Economic Psychology, 41, 101-113. https://doi.org/10.1016/j.joep.2013.02.006

Andersen. S., Harrison, G. W., Lau, M. I., \& Rutström, E. E. (2008). Risk aversion in game shows. Research in Experimental Economics, 12, 361-406. https://doi.org/10.1016/S0193-2306(08)00008-2

Beetsma, R. M., \& Schotman, P. C. (2001). Measuring risk attitudes in a natural experiment: Data from the television game show Lingo. Economic Journal, 111(474), 821-848. 
https://doi.org/10.1111/1468-0297.00661

Bell, D. E. (1982). Regret in decision making under uncertainty. Operations Resarch, 30, 961-981. https://doi.org/10.1287/opre.30.5.961

Bell, D. E. (1985). Disaapointment in decision making under uncertainty. Operations Resarch, 33, 1-27. https://doi.org/10.1287/opre.33.1.1

Binswanger, H. P. (1980). Attitudes toward risk: Experimental measurement in rural India. American Journal of Agricultural Economics, 62(3), 395-407. https://doi.org/10.2307/1240194

Binswanger, H. P. (1981). Attitudes toward risk: Theoretical implcations of an experiment in rural Inda. Economic Journal, 91(364), 867-890. https://doi.org/10.2307/2232497

Blavatskyy, P., \& Pogrebna, G. (2007). Testing the predictions of decision theories in a natural experiment when half a million is at stake. Zurich IEER Working Paper, No. 291.

Botti, F., Conte, A., Di Cagno, D., \& D'Ippoliti, C. (2008). Risk attitude in real decision problems. The B.E. Journal of Economic Analysis \& Policy, 8(1), 1-32. https://doi.org/10.2202/1935-1682.1798

Bower, G. (1981).Mood and memory. American Psychologist, 36, 129-148. https://doi.org/10.1037/0003-066X.36.2.129

Capra, C. M. (2004). Mood-driven behavior in strategic interactions. American Economic Review, 94, 367-372. https://doi.org/10.1257/0002828041301885

Clore, G. L., Schwarz, N., \& Conway, M. (1994). Affective causes and consequences od social information processing. In R. S. Wyer, \& T. K. Srull (Eds.), Handbook of social cognition (2nd ed., Vol. 1, pp. 323-418). Hillsdale, NJ: Erlbaum.

Connolly, T., \& Zeelenberg, M. (2002). Regret in decision making. Current Directions in Psychological Science, 11(6), 212-216. https://doi.org/10.1111/1467-8721.00203

De Roos, N., \& Sarafidis, Y. (2010). Decision making under risk in deal or no deal. Journal of Applied Econometrics, 25(6), 987-1027. https://doi.org/10.1002/jae.1110

Deck, C., Lee, J., \& Reyes, J. (2008). Risk attitudes in large stake gambles: Evidence from a game show. Applied Economics, 40, 41-55. https://doi.org/10.1080/00036840701235704

Druckman, J. N., \& McDermott, R. (2008). Emotion and the framing of risky choice. Polit Behav, 30, 297-321. https://doi.org/10.1007/s11109-008-9056-y

Ekman, P. (1994). Strong evidence for universals in facial expressions: A reply to Russell's mistaken Ccitique. Psychological Bulletin, 115, 268-287. https://doi.org/10.1037/0033-2909.115.2.268

Ekman, P. (2007). Emotions Revealed. Second Additon: Recognizing Faces and Feelings to Improve Communication and Emotional Life. New York:Henry Holt and Company.

Ekman, P., \& Friesen, W. V. (1975). Unmasking the face. Englewood Cliffs, NJ: Prentice Hall.

Elster, J. (1998). Emotions and economic theory. Journal of Economic Literature, 36(1), 47-74.

Fessler, D. M. T., Pillsworth, E. G., \& Flamson, T. J. (2004). Angry man and disgusted women: An evolutionary approach to the influence of emotions on risk taking. Organizational Behavior and Human Decision Processes, 97, 107-123. https://doi.org/10.1016/j.obhdp.2004.06.006

Forgas, J. P. (1995). Mood and judgment: The affect infusion (AIM). Psychological Bulletin, 117, 39-66. https://doi.org/10.1037/0033-2909.117.1.39

Fullenkamp, C., Tenorio, R., \& Battalio, R. (2003). Assessing individual risk attitudes using field data from lottery games. Review of Economics and Statistics, 85(1), 218-226. https://doi.org/10.1162/rest.2003.85.1.218

Gertner, R. (1993). Game shows and economic behavior: Risk taking on 'card sharks'. Quarterly Journal of Economics, 108(2), 507-521. https://doi.org/10.2307/2118342

Hartley, R., Lanot, G., \& Walker, I. (2005). Who really wants to be a millionaire: Estimates of risk aversion from game show data. Working paper, University of Warwick.

Hersch, P. L., \& McDougall, G. S. (1997). Decision making under uncertainty when the stakes are high: Evidence from a lottery game show. Southern Economic Journal, 64(1), 75-84. https://doi.org/10.2307/1061038 
Hyoun, J. G., Kwak, K. C., Lee, D. J., \& Chun, M. G. (2003). Emotion recognition from the facial image and speech signa. SICE Annual Conference in Fukui, August 4-6, Fukui University, Japan.

Isen, A. M. (1997). Positive affect and decision making. In W. M. Goldstein, \& R. M. Hogarth (Eds.), Resarch on judgment and decision making: Currents, connections and controversies (pp. 509-537). Cambridge, UK:Cambridge University Press.

Isen, A. M., \& Patrick, R. (1983). The effect of positive feelings on risk taking: When the chips are down. Orginisational Behavior and Human Decision Processes, 31, 194-202. https://doi.org/10.1016/0030-5073(83)90120-4

Isen, A. M., Means, B., Patrick, R., \& Nowicki, G. (1982). Some factors influencing decision making strategy and risk taking. In M. S. Clark, \& S. T. Fiske (Eds.), Affect and cognition: The seventeenth annual carneige eymposium on cognition (pp. 243-261). Englewood Cliffs, NJ: L. Erlbaum Associates.

Johnson, E., \& Tversky, A. (1983). Affect, generalization and the perception of risk. Journal of Personality and Social Psychology, 45, 20-31. https://doi.org/10.1037/0022-3514.45.1.20

Kachelmeier, S. J., \& Shehata, M. (1992). Examining risk prefrences under high monetary incentives: Experimental evidence from the people's republic of China. American Economic Review, 82(5), 1120-41.

Kahneman, D., \& Tversky, A. (1979). Prospect theory: An analysis of decision under risk. Econometrica, 47(2), 263-91. https://doi.org/10.2307/1914185

Kugler, T., Connoly, T., \& Ordonez, L. D. (2012). Emotion, decision and risk: Betting on gambles versus betting on people. Journal of Behavioral Decision Making, 25, 123-134. https://doi.org/10.1002/bdm.724

Larrick, R. P., \& Boles, T. L. (1995). Avoiding regret in decisions with feedback: A negotiation example. Organizational Behavior and Human Decision Processes, 63(1), 87-97. https://doi.org/10.1006/obhd.1995.1064

Lerner, J. S., \& Keltner. (2001). Fear, anger and risk. Journal of Personality and Social Psychology, 81, 146-59. http://dx.doi.org/10.1037//O022-3514.81.1.146

Lerner, J. S., \& Tiedens, L. Z. (2006). Portrait of the angry decision maker: How appraisal tendencies shape anger's influence on cognition. Journal of Behavioral Decision Making, 19, 115-137. https://doi.org/10.1002/bdm.515

Loewenstein, G., \& Lerner, J. S. (2003). The role of affect in decision making. In R. Davidson, K. Schrer, \& H. Goldsmith (Eds.), Handbook of affective science. Oxford, UK: Oxford University Press.

Loomes, G., \& Sugden, R. (1982). Regret theory: An alternative theory of rational choice under uncertainty. Economic Journal, 92, 805-824. https://doi.org/10.2307/2232669

March, J. (1978). Bounded rationality, ambiguity and the engineering of choice. Bell Journal of Economics, 9 , 587-608. https://doi.org/10.2307/3003600

Metrick, A. (1995). A Natural experiment in jeopardy! American Economic Review, 85(1), 240-253.

Nguyen, Y., \& Noussair, C. N. (2014). Risk aversion and emotions. Pacific Economic Review, 19(3), 296-312. https://doi.org/10.1111/1468-0106.12067

Post, T., Baltussen, G., Assem, M., \& Thaler, R. (2008). Deal or no deal? Decision making under risk in a large-payoff game show. American Economic Review, 98(1), 38-71. https://doi.org/10.1257/aer.98.1.38

Raghunathan, R., \& Pham, M. T. (1999). All negative moods are not equal: Motivational influences of anxiety and sadness on decision making. Organizational Behavior and Human Decision Processes, 79, 56-77. https://doi.org/10.1006/obhd.1999.2838

Rangel, A., Camerer, C., \& Monrague, P. R. (2008). A framework for studying the neurobiology of value-based decision making. Nature Reviews Neuroscience, 9, 545-556. https://doi.org/10.1038/nrn2357

Schwarz, N. (2000). Emotion, cognition and decision making. Cognition and Emotion, 14(4), 433-440. https://doi.org/10.1080/026999300402745

Schwarz, N., \& Clore, G. L. (1983). Mood, misattribution and judgments of well-being: Informative and directive functions of affective states. Journal of Personality and Social Psychology, 45, 513-523. https://doi.org/10.1037/0022-3514.45.3.513

Seymour, B., \& Dolan, R. (2008). Emotion, decision making and the amigdala. Neuron, 58, 662-671. 
https://doi.org/10.1016/j.neuron.2008.05.020

Simonsohn, U. (2007). Clouds make nerds look good: Field evidence of the influence of incitendal factors on decision making. Journal Behavioral Decision Making, 20(143), 152. https://doi.org/10.1002/bdm.545

Sitkin, S. B., \& Weingart, L. R. (1995). Determinants of risky decision making behavior: A test of the mediating role of role perceptions and prospensity. Academy of Management Journal, 38, 1537-1592. https://doi.org/10.2307/256844

Smith, C. A., \& Ellsworth, P. C. (1985). Patterns of cognitive appraisal in emotion. Journal of Personality and Social Psychology, 48(4), 813-838. https://doi.org/10.1037/0022-3514.48.4.813

Taşdemir, M. (2007). Belirsizlik altında tercihler ve beklenen fayda modelinin yetersizlikleri. Sosyal Bilimler Dergisi, 1, 307-318.

Tiedens, L. Z., \& Linton, S. (2001). Judgment under emotional certainty and uncertainty: The effects of spesific emotions on information processing. Journal of Personality and Social Psychology, 81, 973-988. http://dx.doi.org/10.1037//OO22-3514.81.6.973

Tsai, M. H., \& Young, M. J. (2010). Anger, fear and escalation of commitment. Cognition and Emotion, 24, 962-973. https://doi.org/10.1080/02699930903050631

Von Neumann, J., \& Morgenstern, O. (1947). Theory of games and economic behavior. New Jersey: Princeton University Press.

\section{Notes}

Note 1. See. Hans P. Binswanger $(1980,1981)$ and Steven J. Kachelmeier and Mohamed Shehata (1992)

Note 2. https://www.projectoxford.ai/demo/emotion

\section{Appendix}

\section{Appendix 1.}

\begin{tabular}{|c|c|c|c|c|c|c|c|c|c|c|c|c|c|c|c|c|}
\hline \multicolumn{17}{|c|}{26 boxed version } \\
\hline \multirow{2}{*}{$\begin{array}{c}\text { Emotion } \\
\text { Rounds }\end{array}$} & \multicolumn{4}{|c|}{ Anger } & \multicolumn{4}{|c|}{ Contempt } & \multicolumn{4}{|c|}{ Disgust } & \multicolumn{4}{|c|}{ Fear } \\
\hline & Mean & S.Dev & Min & Max & Mean & S.Dev & Min & Max & Mean & S.Dev & Min & Max & Mean & S.Dev & Min & Max \\
\hline $1(\mathrm{~N}=55)$ & 0,008 & 0,046 & 0 & 0,34 & 0,006 & 0,013 & 0 & 0,07 & 0,008 & 0,023 & 0 & 0,12 & 0,001 & 0,003 & 0 & 0,02 \\
\hline $2(\mathrm{~N}=55)$ & 0,004 & 0,020 & 0 & 0,15 & 0,016 & 0,035 & 0 & 0,24 & 0,013 & 0,067 & 0 & 0,50 & 0,001 & 0,002 & 0 & 0,01 \\
\hline $3(\mathrm{~N}=54)$ & 0,006 & 0,017 & 0 & 0,10 & 0,008 & 0,014 & 0 & 0,09 & 0,010 & 0,039 & 0 & 0,26 & 0,001 & 0,004 & 0 & 0,02 \\
\hline $4(\mathrm{~N}=52)$ & 0,003 & 0,010 & 0 & 0,06 & 0,008 & 0,012 & 0 & 0,05 & 0,002 & 0,004 & 0 & 0,02 & 0,000 & 0,002 & 0 & 0,01 \\
\hline $5(\mathrm{~N}=52)$ & 0,016 & 0,093 & 0 & 0,67 & 0,010 & 0,017 & 0 & 0,08 & 0,006 & 0,018 & 0 & 0,12 & 0,001 & 0,006 & 0 & 0,04 \\
\hline $6(\mathrm{~N}=50)$ & 0,021 & 0,120 & 0 & 0,85 & 0,015 & 0,029 & 0 & 0,18 & 0,010 & 0,031 & 0 & 0,20 & 0,001 & 0,004 & 0 & 0,02 \\
\hline $7(\mathrm{~N}=46)$ & 0,001 & 0,003 & 0 & 0,02 & 0,020 & 0,108 & 0 & 0,74 & 0,010 & 0,045 & 0 & 0,30 & 0,001 & 0,002 & 0 & 0,01 \\
\hline $8(\mathrm{~N}=35)$ & 0,001 & 0,003 & 0 & 0,02 & 0,013 & 0,038 & 0 & 0,22 & 0,004 & 0,008 & 0 & 0,03 & 0,003 & 0,009 & 0 & 0,05 \\
\hline $9(\mathrm{~N}=30)$ & 0,002 & 0,006 & 0 & 0,03 & 0,006 & 0,009 & 0 & 0,04 & 0,003 & 0,008 & 0 & 0,03 & 0,002 & 0,006 & 0 & 0,00 \\
\hline Emotion & \multicolumn{4}{|c|}{ Happiness } & \multicolumn{4}{|c|}{ Neutral } & \multicolumn{4}{|c|}{ Sadness } & \multicolumn{4}{|c|}{ Surprise } \\
\hline Rounds & Mean & S.Dev & Min & Max & Mean & S.Dev & Min & Max & Mean & S.Dev & Min & Max & Mean & S.Dev & Min & Max \\
\hline $1(\mathrm{~N}=55)$ & 0,057 & 0,401 & 0 & 1 & 0,338 & 0,356 & 0 & 1 & 0,013 & 0,036 & 0 & 0,20 & 0,045 & 0,136 & 0 & 0,69 \\
\hline $2(\mathrm{~N}=55)$ & 0,508 & 0,384 & 0 & 1 & 0,399 & 0,341 & 0 & 0,98 & 0,022 & 0,066 & 0 & 0,43 & 0,033 & 0,122 & 0 & 0,85 \\
\hline $3(\mathrm{~N}=54)$ & 0,516 & 0,399 & 0 & 1 & 0,407 & 0,354 & 0 & 0,97 & 0,018 & 0,044 & 0 & 0,24 & 0,031 & 0,105 & 0 & 0,58 \\
\hline $4(\mathrm{~N}=52)$ & 0,470 & 0,422 & 0 & 1 & 0,460 & 0,389 & 0 & 1 & 0,025 & 0,094 & 0 & 0,61 & 0,029 & 0,140 & 0 & 0,97 \\
\hline $5(\mathrm{~N}=52)$ & 0,590 & 0,382 & 0 & 1 & 0,330 & 0,326 & 0 & 0,96 & 0,023 & 0,083 & 0 & 0,59 & 0,019 & 0,067 & 0 & 0,45 \\
\hline $6(\mathrm{~N}=50)$ & 0,386 & 0,358 & 0 & 1 & 0,477 & 0,317 & 0 & 1 & 0,010 & 0,022 & 0 & 0,11 & 0,074 & 0,138 & 0 & 0,81 \\
\hline $7(\mathrm{~N}=46)$ & 0,543 & 0,424 & 0 & 1 & 0,349 & 0,370 & 0 & 0,98 & 0,028 & 0,091 & 0 & 0,53 & 0,045 & 0,155 & 0 & 0,96 \\
\hline $8(\mathrm{~N}=35)$ & 0,452 & 0,370 & 0 & 1 & 0,435 & 0,334 & 0 & 0,95 & 0,020 & 0,041 & 0 & 0,17 & 0,069 & 0,176 & 0 & 0,82 \\
\hline $9(\mathrm{~N}=30)$ & 0,531 & 0,415 & 0 & 1 & 0,415 & 0,403 & 0 & 1 & 0,004 & 0,006 & 0 & 0,02 & 0,024 & 0,074 & 0 & 0,37 \\
\hline
\end{tabular}


Appendix 2.

\begin{tabular}{|c|c|c|c|c|c|c|c|c|c|c|c|c|c|c|c|c|}
\hline \multicolumn{17}{|c|}{24 boxed version } \\
\hline \multirow{2}{*}{$\begin{array}{l}\text { Emotion } \\
\text { Rounds } \\
\end{array}$} & \multicolumn{4}{|c|}{ Anger } & \multicolumn{4}{|c|}{ Contempt } & \multicolumn{4}{|c|}{ Disgust } & \multicolumn{4}{|c|}{ Fear } \\
\hline & Mean & S.Dev & Min & Max & Mean & S.Dev & Min & Max & Mean & S.Dev & Min & Max & Mean & S.Dev & Min & Max \\
\hline $1(\mathrm{~N}=16)$ & 0,001 & 0,054 & 0 & 0,02 & 0,035 & 0,078 & 0 & 0,25 & 0,001 & 0,003 & 0 & 0,01 & 0,000 & 0,002 & 0 & 0,01 \\
\hline $2(\mathrm{~N}=16)$ & 0,000 & 0,000 & 0 & 0,00 & 0,009 & 0,009 & 0 & 0,03 & 0,002 & 0,003 & 0 & 0,01 & 0,001 & 0,003 & 0 & 0,01 \\
\hline $3(\mathrm{~N}=16)$ & 0,001 & 0,003 & 0 & 0,01 & 0,005 & 0,006 & 0 & 0,02 & 0,002 & 0,003 & 0 & 0,01 & 0,000 & 0,001 & 0 & 0,01 \\
\hline $4(\mathrm{~N}=16)$ & 0,000 & 0,000 & 0 & 0 & 0,016 & 0,035 & 0 & 0,13 & 0,000 & 0,001 & 0 & 0,01 & 0,000 & 0,003 & 0 & 0,01 \\
\hline $5(\mathrm{~N}=15)$ & 0,001 & 0,002 & 0 & 0,01 & 0,021 & 0,055 & 0 & 0,22 & 0,001 & 0,002 & 0 & 0,01 & 0,000 & 0,000 & 0 & 0 \\
\hline $6(\mathrm{~N}=15)$ & 0,001 & 0,002 & 0 & 0,01 & 0,025 & 0,039 & 0 & 0,12 & 0,003 & 0,004 & 0 & 0,01 & 0,002 & 0,005 & 0 & 0,02 \\
\hline $7(\mathrm{~N}=11)$ & 0,001 & 0,002 & 0 & 0,01 & 0,007 & 0,015 & 0 & 0,05 & 0,001 & 0,003 & 0 & 0,01 & 0,000 & 0,000 & 0 & 0 \\
\hline Emotion & \multicolumn{4}{|c|}{ Happiness } & \multicolumn{4}{|c|}{ Neutral } & \multicolumn{4}{|c|}{ Sadness } & \multicolumn{4}{|c|}{ Surprise } \\
\hline Rounds & Mean & S.Dev & Min & Max & Mean & S.Dev & Min & Max & Mean & S.Dev & Min & Max & Mean & S.Dev & Min & Max \\
\hline $1(\mathrm{~N}=16)$ & 0,693 & 0,325 & 0,01 & 1 & 0,252 & 0,294 & 0 & 0,86 & 0,011 & 0,036 & 0 & 0,15 & 0,003 & 0,013 & 0 & 0,05 \\
\hline $2(\mathrm{~N}=16)$ & 0,475 & 0,396 & 0 & 1 & 0,456 & 0,377 & 0 & 0,97 & 0,017 & 0,040 & 0 & 0,13 & 0,037 & 0,136 & 0 & 0,55 \\
\hline $3(\mathrm{~N}=16)$ & 0,499 & 0,418 & 0 & 1 & 0,458 & 0,382 & 0 & 0,95 & 0,019 & 0,045 & 0 & 0,95 & 0,011 & 0,037 & 0 & 0,15 \\
\hline $4(\mathrm{~N}=16)$ & 0,462 & 0,441 & 0 & 1 & 0,485 & 0,409 & 0 & 1 & 0,025 & 0,082 & 0 & 0,33 & 0,008 & 0,026 & 0 & 0,10 \\
\hline $5(\mathrm{~N}=15)$ & 0,318 & 0,395 & 0 & 0,98 & 0,621 & 0,392 & 0,02 & 1 & 0,013 & 0,027 & 0 & 0,08 & 0,021 & 0,064 & 0 & 0,25 \\
\hline $6(\mathrm{~N}=15)$ & 0,131 & 0,283 & 0 & 0,94 & 0,791 & 0,310 & 0,04 & 0,99 & 0,039 & 0,067 & 0 & 0,22 & 0,005 & 0,009 & 0 & 0,03 \\
\hline $7(\mathrm{~N}=11)$ & 0,286 & 0,422 & 0 & 0,99 & 0,682 & 0,404 & 0,01 & 1 & 0,019 & 0,038 & 0 & 0,12 & 0,000 & 0,001 & 0 & 0 \\
\hline
\end{tabular}

\section{Copyrights}

Copyright for this article is retained by the author(s), with first publication rights granted to the journal.

This is an open-access article distributed under the terms and conditions of the Creative Commons Attribution license (http://creativecommons.org/licenses/by/4.0/). 